\title{
Age at diagnosis indicated poor prognosis in locoregionally advanced nasopharyngeal carcinoma
}

\author{
Lu-Ning Zhang1,2,*, Xing-Sheng Qiu${ }^{3, *}$, Pu-Yun OuYang ${ }^{2, *}$, Yao Xiao², Xiao-Wen \\ Lan ${ }^{2}$, Wuguo Deng ${ }^{2}$, Fang-Yun $\mathrm{Xie}^{2}$ and Xi-Cheng Wang ${ }^{1}$ \\ ${ }^{1}$ Department of Oncology, The First Affiliated Hospital of Guangdong Pharmaceutical University, Guangzhou, China \\ ${ }^{2}$ Sun Yat-sen University Cancer Center, State Key Laboratory of Oncology in South China, Collaborative Innovation Center \\ for Cancer Medicine, Guangzhou, Guangdong, China \\ ${ }^{3}$ Department of Radiation Oncology, Sun Yat-sen Memorial Hospital, Sun Yat-sen University, Guangzhou, China \\ * Co-first authors \\ Correspondence to: Xi-Cheng Wang, email: 13902400598@126.com
}

Fang-Yun Xie, email: xiefy@sysucc.org.cn

Wuguo Deng, email: dengwg@sysucc.org.cn

Keywords: age; concurrent chemoradiotherapy; distant metastasis; mortality; nasopharyngeal carcinoma

Received: August 10,2016 Accepted: September 29, $2016 \quad$ Published: October 09, 2016

\section{ABSTRACT}

Background: Effect of age at diagnosis on treatment failure and mortality was rarely evaluated in nasopharyngeal carcinoma.

Methods: We analyzed 1252 patients staged III-IVb and underwent concurrent chemoradiotherapy. Age was categorized as 20 to 49 years $(n=804), 50$ to 59 years $(n=282)$ and 60 years or older $(n=166)$. Distant metastasis-free survival (DMFS), cancer-specific survival (CSS), overall survival (OS) and locoregional relapse-free survival (LRFS) were assessed by age group.

Results: The 4-years DMFS decreased with age group (86.7\% [20-49 years], $86.7 \%$ [50-59 years], $77.1 \%$ [ $\geq 60$ years]; $P=0.014$ ); likewise, 4-years CSS were $91.0 \%, 87.4 \%$ and $74.2 \%(P<0.001) ; 4$-years 0 were $90.8 \%, 87.4 \%$ and $73.6 \%$ $(P<0.001)$, respectively. In multivariate analysis, compared with patients aged 20 to 49 years, DMFS decreased with age for patients aged 50 to 59 years (HR=1.10, 95\% CI 0.77-1.57) and aged 60 years or older ( HR=1.75, 95\% CI 1.20-2.56) $(P=0.015)$. Similarly, both CSS and OS were inferior in patients aged 50 to 59 years $(H R=1.77$, 95\% CI 1.25-2.52 for CSS; HR=1.71, 95\% CI 1.21-2.43 for OS) and aged 60 or older (HR=3.73, 95\% CI 2.63-5.29 for CSS; HR=3.96, 95\% CI 2.83-5.54 for OS) $(P<0.001)$. Yet age did not affect LRFS in univariate and multivariate analysis.

Conclusions: Increasing age at diagnosis of locoregionally advanced nasopharyngeal carcinoma was associated with higher risk of distant metastasis and mortality.

\section{INTRODUCTION}

Nasopharyngeal carcinoma (NPC) is a squamouscell carcinoma specially endemic in Southern China. Almost $70 \%$ patients are initially diagnosed with locoregionally advanced disease [1], except those detected by regular physical examination of the nasopharynx. Unfortunately, these patients can hardly avoid the high risk of distant metastasis [2], treatment failure and mortality [3], despite the assistance of recommended concurrent chemotherapy plus advanced intensity-modulated radiotherapy.

Apart from such classic tumor-related factors as TNM stage [1] and copy number of Epstein-Barr viral deoxyribonucleic acid $[4,5]$, patient characteristics (e.g., sex [6]) may be associated with NPC outcomes as well. Interestingly, prior randomized controlled trials $[7,8]$ hinted at age-specific association with mortality, while others $[9,10]$ observed no association at all. Undoubtedly, strict eligibility criteria make the trial cohort unlikely to 
Table 1: Baseline characteristics by age at diagnosis

\begin{tabular}{|c|c|c|c|c|}
\hline & $20-49$ years $(n=804)$ & $50-59$ years $(n=282)$ & $\geq 60$ years $(n=166)$ & $P$ \\
\hline Sex & & & & 0.483 \\
\hline Male & $586(72.9)$ & $195(69.1)$ & $120(72.3)$ & \\
\hline Female & $218(27.1)$ & $87(30.9)$ & $46(27.7)$ & \\
\hline Histology * & & & & 0.914 \\
\hline $\mathrm{I}+\mathrm{II}$ & $57(7.1)$ & $18(6.4)$ & $11(6.6)$ & \\
\hline III & 747 (92.9) & $264(93.6)$ & $155(93.4)$ & \\
\hline VCA-IgA & & & & 0.007 \\
\hline$<80$ & $135(16.8)$ & $44(15.6)$ & $13(7.8)$ & \\
\hline $80-320$ & $277(34.5)$ & $95(33.7)$ & $48(28.9)$ & \\
\hline$\geq 320$ & $392(48.8)$ & $143(50.7)$ & $105(63.3)$ & \\
\hline EA-IgA & & & & 0.007 \\
\hline$<10$ & $231(28.7)$ & $72(25.5)$ & $27(16.3)$ & \\
\hline $10-40$ & $255(31.7)$ & $86(30.5)$ & $52(31.3)$ & \\
\hline$\geq 40$ & $318(39.6)$ & $124(44.0)$ & $87(52.4)$ & \\
\hline T-stage & & & & 0.373 \\
\hline $\mathrm{T} 1+\mathrm{T} 2$ & $82(10.2)$ & $24(8.5)$ & $21(12.7)$ & \\
\hline $\mathrm{T} 3+\mathrm{T} 4$ & $722(89.8)$ & $258(91.5)$ & $145(87.3)$ & \\
\hline N-stage & & & & 0.563 \\
\hline $\mathrm{N} 0+\mathrm{N} 1$ & $576(71.6)$ & $207(73.4)$ & $114(68.7)$ & \\
\hline $\mathrm{N} 2+\mathrm{N} 3$ & $228(28.4)$ & $75(26.6)$ & $52(31.3)$ & \\
\hline Clinical stage & & & & 0.010 \\
\hline III & $522(64.9)$ & $175(62.1)$ & $87(52.4)$ & \\
\hline IV & $282(35.1)$ & $107(37.9)$ & $79(47.6)$ & \\
\hline Radiotherapy & & & & 0.378 \\
\hline 2DCRT & $496(61.7)$ & $174(61.7)$ & $93(56.0)$ & \\
\hline IMRT & $308(38.3)$ & $108(38.3)$ & $73(44.0)$ & \\
\hline
\end{tabular}

Abbreviations: $\mathrm{IMRT}=$ intensity-modulated radiotherapy, $2 \mathrm{DCRT}=$ two-dimensional conventional radiotherapy, $\mathrm{VCA}=\mathrm{viral}$ capsid antigen, $\mathrm{EA}=$ early antigen, $\operatorname{Ig} \mathrm{A}=$ immunoglobulin $\mathrm{A}$

* Based on the criteria of WHO histological type (1991): II - Differentiated non-keratinising carcinoma, III - Undifferentiated non-keratinising carcinoma

represent the general cancer population with respect to cancer histology, stage and other basic characteristics. For instance, older patients are often excluded from clinical trials due to age restrictions. Thus the prognostic significance of age was essential to be assessed in a cohort out of trials.

In this study, we aimed to evaluate distant metastasis rate among age groups in locoregionally advanced NPC patients treated with concurrent chemoradiotherapy. Secondarily, age-specific locoregional relapse, cancer specific mortality and overall mortality were evaluated as well.

\section{RESULTS}

A total of 1252 patients (age range, 20-78 years; median age, 45 years) were included, of which 804
(64.2\%) were aged 20 to 49 years (median age, 40 years), $282(22.5 \%)$ were aged 50 to 59 years (median age, 54 years), and $166(13.3 \%)$ were aged 60 years or older (median age, 63 years). As showed in Table 1, there was a significant age-associated increase in higher titer of immunoglobulin A against viral capsid antigen (VCAIgA) and early antigen (EA-IgA). Besides, the proportion of advanced clinical stage increased significantly with age. With median follow-up of 56.9 months (3.5-108.3 months) for patients aged 20 to 49 years, 52.4 months (5.2-107.1 months) for patients aged 50 to 59 years, and 47.6 months (3.3-111.1 months) for patients aged 60 or older respectively, 111 (13.8\%), 42 (14.9\%) and 35 $(21.1 \%)$ patients had distant metastasis. As illustrated in Figure 1, 4-years distant metastasis-free survival (DMFS) significantly decreased from $86.7 \%$ in patients aged 20 to 49 years, $86.7 \%$ in patients aged 50 to 59 years, to $77.1 \%$ 
Table 2: Summary of pivotal prognostic factors in multivariate analysis

\begin{tabular}{|c|c|c|}
\hline & Multivariate hazard ratio (95\% CI) & $\boldsymbol{P}^{\dagger}$ \\
\hline \multicolumn{3}{|c|}{ Distant metastasis-free survival } \\
\hline Age & & 0.015 \\
\hline 20-49 years & 1 (reference) & \\
\hline $50-59$ years & $1.10(0.77-1.57)$ & 0.591 \\
\hline$\geq 60$ years & $1.75(1.20-2.56)$ & 0.004 \\
\hline T-stage $(\mathrm{T} 1+\mathrm{T} 2$ vs T3+T4) & $1.73(1.05-2.86)$ & 0.031 \\
\hline $\mathrm{N}$-stage (N0+N1 vs N2+N3) & $2.44(1.78-3.35)$ & $<0.001$ \\
\hline \multicolumn{3}{|l|}{ Cancer specific survival } \\
\hline \multicolumn{3}{|l|}{ Age } \\
\hline $20-49$ years & 1 (reference) & \\
\hline $50-59$ years & $1.77(1.25-2.52)$ & 0.001 \\
\hline$\geq 60$ years & $3.73(2.63-5.29)$ & $<0.001$ \\
\hline $\mathrm{T}$-stage $(\mathrm{T} 1+\mathrm{T} 2$ vs $\mathrm{T} 3+\mathrm{T} 4)$ & $2.54(1.50-4.31)$ & 0.001 \\
\hline $\mathrm{N}$-stage $(\mathrm{N} 0+\mathrm{N} 1$ vs $\mathrm{N} 2+\mathrm{N} 3)$ & $2.82(2.05-3.87)$ & $<0.001$ \\
\hline \multicolumn{3}{|l|}{ Overall survival } \\
\hline \multicolumn{3}{|l|}{ Age } \\
\hline $20-49$ years & 1 (reference) & \\
\hline $50-59$ years & $1.71(1.21-2.43)$ & 0.003 \\
\hline$\geq 60$ years & $3.96(2.83-5.54)$ & $<0.001$ \\
\hline $\mathrm{T}$-stage (T1+T2 vs $\mathrm{T} 3+\mathrm{T} 4)$ & $2.69(1.59-4.55)$ & $<0.001$ \\
\hline $\mathrm{N}$-stage $(\mathrm{N} 0+\mathrm{N} 1$ vs $\mathrm{N} 2+\mathrm{N} 3)$ & $2.83(2.08-3.85)$ & $<0.001$ \\
\hline \multicolumn{3}{|c|}{ Locoregional relapse-free survival } \\
\hline \multicolumn{3}{|l|}{ Age } \\
\hline $20-49$ years & 1 (reference) & \\
\hline $50-59$ years & $1.19(0.79-1.81)$ & 0.407 \\
\hline$\geq 60$ years & $0.84(0.45-1.58)$ & 0.589 \\
\hline $\mathrm{T}$-stage (T1+T2 vs $\mathrm{T} 3+\mathrm{T} 4)$ & $1.56(0.77-3.14)$ & 0.216 \\
\hline $\mathrm{N}$-stage $(\mathrm{N} 0+\mathrm{N} 1$ vs $\mathrm{N} 2+\mathrm{N} 3)$ & $1.53(0.99-2.37)$ & 0.055 \\
\hline
\end{tabular}

Abbreviations: $\mathrm{CI}=$ confidence interval

$\dagger$ Adjusted for T-stage and N-stage by Enter method, and sex, histology, immunoglobulin A against viral capsid antigen $(<80 / 80$ $320 / \geq 320)$, immunoglobulin A against early antigen $(<10 / 10-40 / \geq 40)$ and radiation technique by Forward Stepwise (Likelihood Ratio) method.

in patients aged 60 or older $(P=0.014)$. Likewise, the 4-years cancer specific survival (CSS) were 91.0\%, 87.4\% and $74.2 \%(P<0.001)$; the 4-years overall survival (OS) were $90.8 \%, 87.4 \%$ and $73.6 \%(P<0.001)$, respectively. In addition, 4-years locoregional relapse-free survival (LRFS) were $91.7 \%, 91.4 \%$ and $94.4 \%(P=0.544)$. When adjusted for unequal distributions among age categories (Table 2) by multivariate analyses, DMFS still decreased with age at diagnosis, with a HR of 1.10 (95\% CI $0.77-$ 1.57 ) for patients aged 50 to 59 years and a HR of 1.75
(95\% CI 1.20-2.56) for patients aged 60 or older $(P=$ $0.015)$. Similarly, both CSS (HR $=1.77,95 \%$ CI 1.25 2.52 for patients aged 50 to 59 years; $\mathrm{HR}=3.73,95 \% \mathrm{CI}$ 2.63-5.29 for patients aged 60 or older; $P<0.001)$ and OS $(\mathrm{HR}=1.71,95 \%$ CI $1.21-2.43$ for patients aged 50 to 59 years; HR $=3.96,95 \%$ CI 2.83-5.54 for patients aged 60 or older; $P<0.001)$ remarkably declined with age. But no association was observed between age and LRFS $(\mathrm{HR}=1.19,95 \% \mathrm{CI} 0.79-1.81$ for patients aged 50 to 59 years; $\mathrm{HR}=0.84,95 \% \mathrm{CI} 0.45-1.58$ for patients aged 60 
Table 3: Association of age with survival in subgroup analysis by tumor stage

\begin{tabular}{|c|c|c|c|c|}
\hline & \multicolumn{2}{|l|}{ Stage III } & \multicolumn{2}{|l|}{ Stage IV } \\
\hline & $\begin{array}{l}\text { Multivariate hazard } \\
\text { ratio }(95 \% \mathrm{CI})\end{array}$ & $\boldsymbol{P}^{\dot{r}}$ & $\begin{array}{l}\text { Multivariate hazard } \\
\text { ratio }(95 \% \mathrm{CI})\end{array}$ & $\boldsymbol{P}^{\dot{H}}$ \\
\hline \multicolumn{5}{|c|}{ Distant metastasis-free survival } \\
\hline $20-49$ years & 1 (reference) & & 1 (reference) & \\
\hline $50-59$ years & $1.24(0.75-2.06)$ & 0.407 & $0.90(0.55-1.48)$ & 0.671 \\
\hline$\geq 60$ years & $1.88(1.06-3.33)$ & 0.032 & $1.45(0.87-2.42)$ & 0.150 \\
\hline \multicolumn{5}{|c|}{ Cancer specific survival } \\
\hline $20-49$ years & 1 (reference) & & 1 (reference) & \\
\hline $50-59$ years & $2.31(1.41-3.79)$ & 0.001 & $1.28(0.77-2.12)$ & 0.338 \\
\hline$\geq 60$ years & $3.67(2.13-6.33)$ & $<0.001$ & $3.34(2.13-5.23)$ & $<0.001$ \\
\hline \multicolumn{5}{|c|}{ Overall survival } \\
\hline $20-49$ years & 1 (reference) & & 1 (reference) & \\
\hline $50-59$ years & $2.31(1.41-3.79)$ & 0.001 & $1.20(0.73-1.98)$ & 0.476 \\
\hline$\geq 60$ years & $3.86(2.26-6.59)$ & $<0.001$ & $3.46(2.25-5.33)$ & $<0.001$ \\
\hline \multicolumn{5}{|c|}{ Locoregional relapse-free survival } \\
\hline $20-49$ years & 1 (reference) & & 1 (reference) & \\
\hline $50-59$ years & $1.27(0.72-2.22)$ & 0.411 & $1.09(0.59-2.04)$ & 0.777 \\
\hline$\geq 60$ years & $0.95(0.40-2.23)$ & 0.899 & $0.69(0.27-1.76)$ & 0.430 \\
\hline
\end{tabular}

or older; $P=0.551)$.

Since increasing age was correlated with more advanced tumor stage (Table 1), subgroup analyses by stage were conducted to exclude residual confounding (Table 3). Among patients with stage III, multivariate analyses revealed similar results. Within strata of stage IV, increasing age was consistently correlated with decreased CSS and OS, but not the risk of distant metastasis or locoregional relapse.

In order to test the robustness of the cutoff points of age, we conducted a second analysis by regarding age as a continuous variable. As a result, an increased risk of distant metastasis (univariate $\mathrm{HR}=1.02,95 \%$ CI 1.00 $1.03, P=0.009$; multivariate $\mathrm{HR}=1.02,95 \%$ CI 1.01 $1.03, P=0.006$ ), cancer-specific mortality (univariate HR $=1.05,95 \%$ CI 1.04-1.06, $P<0.001$; multivariate $\mathrm{HR}=$ $1.05,95 \%$ CI $1.04-1.06, P<0.001)$ and overall mortality (univariate $\mathrm{HR}=1.05,95 \%$ CI 1.04-1.07, $P<0.001$; multivariate $\mathrm{HR}=1.05,95 \%$ CI $1.04-1.07, P<0.001)$ by age was confirmed again. Nevertheless, age was not found to be associated with LRFS (univariate HR $=1.01,95 \%$ CI $0.99-1.02, P=0.509$; multivariate $\mathrm{HR}=1.00,95 \% \mathrm{CI}$ $0.99-1.02, P=0.467)$.
To investigate whether the association between age and DMFS, CSS and OS was of linear effect or if there was a specific turning point, age was finally categorized into five groups (Table 4). Resultantly, patients younger than 55 years had similar risk of distant metastasis. But the risk of distant metastasis would elevate with increasing age for patients aged 55 years or older. Moreover, CSS and OS significantly decreased with age, especially for patients aged 45 years or older, whereas LRFS was again not correlated with age.

\section{DISCUSSION}

Our major finding was that older patients had higher risk of distant metastasis and cancer-specific or overall mortality, independent of host factor, tumor characteristics and radiation technique.

Several tumor characteristics potentially biased our findings. Increasing age correlated with higher titer of VCA-IgA and EA-IgA and more advanced tumor stage. But multivariate analyses adjusted for these tumor characteristics and subgroup analyses by tumor stage did not significantly alter the results. 
Table 4: Survival outcomes by age at diagnosis (five groups).

\begin{tabular}{|c|c|c|}
\hline & Multivariate hazard ratio $(95 \% \mathrm{CI})$ & $P^{\dagger}$ \\
\hline \multicolumn{3}{|c|}{ Distant metastasis-free survival } \\
\hline 20-39 years & 1 (reference) & \\
\hline 40-44 years & $0.99(0.62-1.59)$ & 0.961 \\
\hline $45-49$ years & $1.38(0.89-2.13)$ & 0.147 \\
\hline $50-54$ years & $1.19(0.72-1.96)$ & 0.497 \\
\hline$\geq 55$ years & $1.58(1.08-2.31)$ & 0.019 \\
\hline \multicolumn{3}{|c|}{ Cancer specific survival } \\
\hline 20-39 years & 1 (reference) & \\
\hline $40-44$ years & $0.92(0.52-1.62)$ & 0.770 \\
\hline $45-49$ years & $1.80(1.12-2.91)$ & 0.016 \\
\hline $50-54$ years & $2.04(1.23-3.36)$ & 0.006 \\
\hline$\geq 55$ years & $3.16(2.13-4.69)$ & $<0.001$ \\
\hline \multicolumn{3}{|c|}{ Overall survival } \\
\hline 20-39 years & 1 (reference) & \\
\hline $40-44$ years & $0.94(0.54-1.63)$ & 0.814 \\
\hline $45-49$ years & $1.87(1.17-3.00)$ & 0.009 \\
\hline $50-54$ years & $2.12(1.28-3.51)$ & 0.003 \\
\hline$\geq 55$ years & $3.32(2.25-4.92)$ & $<0.001$ \\
\hline \multicolumn{3}{|c|}{ Locoregional relapse-free survival } \\
\hline 20-39 years & 1 (reference) & \\
\hline 40-44 years & $1.06(0.62-1.84)$ & 0.824 \\
\hline $45-49$ years & $1.22(0.71-2.09)$ & 0.475 \\
\hline $50-54$ years & $0.98(0.52-1.86)$ & 0.960 \\
\hline$\geq 55$ years & $1.24(0.76-2.03)$ & 0.385 \\
\hline
\end{tabular}

Abbreviations: $\mathrm{CI}=$ confidence interval

$\dagger$ Adjusted for T-stage and N-stage by Enter method, and sex, histology, immunoglobulin A against viral capsid antigen $(<80 / 80-320 / \geq 320)$, immunoglobulin A against early antigen $(<10 / 10-40 / \geq 40)$, and radiation technique by Forward Stepwise (Likelihood Ratio) method.

Our finding was highly consistent with prior reports in $[7,8]$ and out of $[16,17]$ clinical trials. However, age showed no association with survival in another two trials that focused on the effect of concurrent chemotherapy [10] and adjuvant chemotherapy [9] respectively. Of note, age distribution of included patients was greatly biased by the specific selection criteria of trials, whereas randomization of patients to treatment and control arms cannot guarantee balanced characteristics across age group. In addition, patients were separated to two groups at the age point of 45 years in these two trials. This cutoff point maybe underestimated or even falsely covered the association of age with survival.

Several mechanisms may possibly explain the observed results. Firstly, older patients may experience undertreatment. Previous studies [13, 18] showed that less than $40 \%$ of elderly NPC patients with locoregionally advanced disease received combined chemoradiotherapy. Despite all included patients in our study underwent standard concurrent chemoradiotherapy, more older patients indeed tended to receive lower total dose $\left(<200 \mathrm{mg} / \mathrm{m}^{2}\right)$ of concurrent chemotherapy $(P=$ 0.016). Considering the inferior outcome of concurrent chemotherapy with cisplatin below $200 \mathrm{mg} / \mathrm{m}^{2}$ [19], older patients possibly achieved poor survival. Next, the incidence of comorbidities significantly increased with age in this sort of cancer [20]. Patients with comorbidities were more likely to experience undertreatment, and comorbidity itself indicated poor prognosis in locoregionally advanced NPC [20]. Besides, older patients were found to be those had higher titer of VCA-IgA and EA-IgA and diagnosed with more advanced clinical stage (Table 1). So it was possible that tumor cells in older patients might be more aggressive and more likely 
to spread to distant organs. In addition, it was assumed that overtreatment may be delivered to older patients, and the consequent adverse events can result in mortality attributed to cancer. However, these relatively healthy patients suffered from higher distant metastasis risk with age as well. So overtreatment maybe exerted a tiny effect in our study. Since the association between age and risk of distant metastasis, cancer-specific and overall mortality was maintained despite the adjustment for various characteristics, other unknown factors might help to cause the results. Perhaps, older patients might respond differently to either the tumor or anticancer therapy.

The major strength of this study was the intensive assessment of age-specific association with risk of distant metastasis, cancer specific and overall mortality in a large cohort close to general population but with utilized treatment and complete follow-up. It is a limitation that data on deoxyribonucleic acid (DNA) copy number of the Epstein-Barr virus was missing in most of cases, but VCA-IgA and EA-IgA were taken as the surrogate for tumor burden. In addition, some patients might be delayed in detecting lung metastasis and consequently have falsely high DMFS rate, owing to the low sensitivity rate of
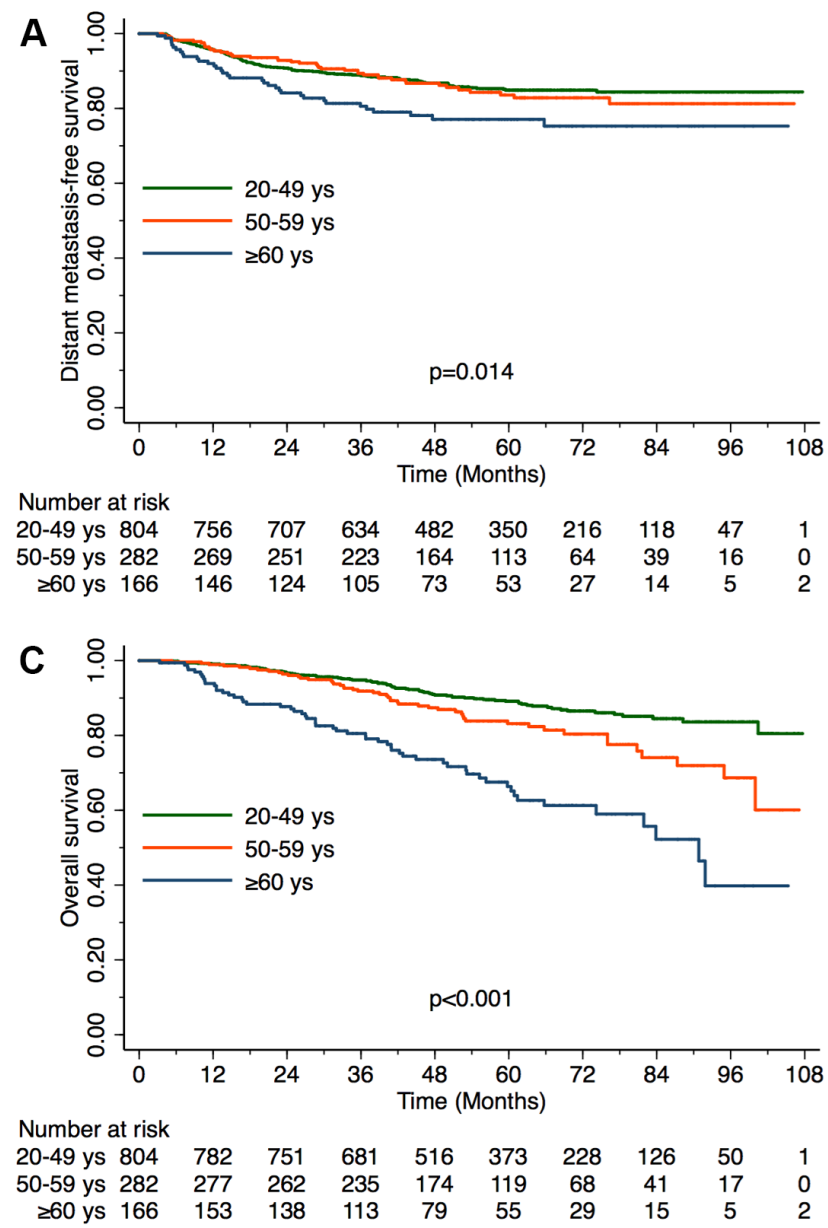

chest radiography compared with $\mathrm{CT}$. But the intrinsic differences in DMFS might scarcely change, as the chance of delay was equal to patients in each arm.

To summarize, this study found increasing risk of distant metastasis, cancer specific and overall mortality with increasing age at diagnosis in locoregionally advanced NPC patients.

\section{MATERIALS AND METHODS}

\section{Patients}

Potentially eligible patients were those diagnosed with NPC between Jan 2005 and Jan 2011 by history and physical examination, hematology and biochemistry profiles, fiberoptic nasopharyngoscopy with biopsy, magnetic resonance imaging (MRI) of the nasopharynx and neck, chest radiography or computed tomography (CT), abdominal sonography or CT, Technetium-99mmethylene diphosphonate (Tc-99-MDP) whole-body bone scan or CT/MRI of bones, and/or [18F] fluorodeoxy
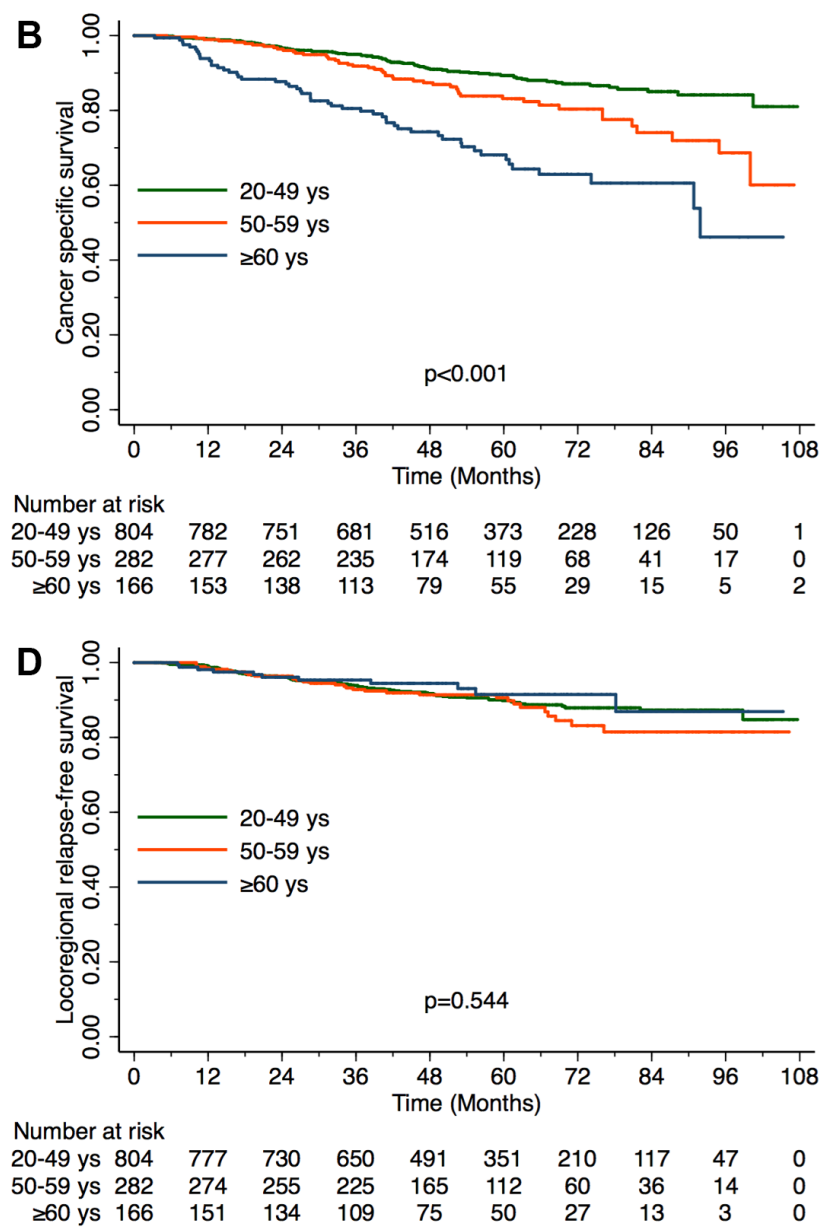

Figure 1: Distant metastasis-free survival (A), cancer specific survival (B), overall survival (C) and locoregional relapse-free survival (D) of patients by age at diagnosis. 
glucose positron emission tomography and computed tomography (PET/CT). The following inclusion criteria were used: (1) age $\geq 20$ years; (2) restaged III-IVa-b based on the 2010 International Union against Cancer/American Joint Committee on Cancer (UICC/AJCC) staging system; (3) treated with concurrent chemoradiotherapy alone; and (4) available data on VCA-IgA and EA-IgA. The exclusion criteria were as follows: (1) receiving anticancer therapy out of our hospital; (2) pregnancy or lactation; (3) a history of previous, synchronous or subsequent malignant tumors; and (4) lack of follow-up.

This study was approved by the Institutional Review Board at our center, and individual informed consent was waived given the anonymous analysis of routine data.

\section{Treatment}

All patients underwent definitive intensitymodulated radiotherapy (IMRT) or two-dimensional conventional radiotherapy (2DCRT) plus concurrent chemotherapy. Cumulative radiation doses were $66 \mathrm{~Gy}$ or greater to the primary tumor, $60 \mathrm{~Gy}$ or greater to involved cervical lymph nodes and 50 Gy or greater to local sites with potential infiltration and uninvolved cervical and supraclavicular areas in 30-33 fractions. Further information of radiation technique had been detailed previously [11]. Concurrent chemotherapy consisted of $80-100 \mathrm{mg} / \mathrm{m}^{2}$ cisplatin- or nedaplatin-based regimen given every three weeks for two to three cycles, or $30-40 \mathrm{mg} /$ $\mathrm{m}^{2}$ cisplatin- or nedaplatin-based regimen or $20-30 \mathrm{mg} /$ $\mathrm{m}^{2}$ docetaxel-based regimen given weekly for up to seven cycles.

\section{Follow-up}

Patients were assessed by similar examination to pretreatment evaluation every 3-6 months during the first 3 years and every 6-12 months thereafter until death, to detect possible relapse or distant metastasis. Salvage treatment including reirradiation, surgery and/or chemotherapy was delivered to patients with confirmed relapse, distant metastasis or persistent disease. Patients without recent examination tests in medical records were followed up by telephone call.

\section{Statistical analysis}

Since sex significantly affected survival of NPC [6] and median age at natural menopause was 50 years in Chinese [12], patients in this study were categorized into 3 age groups: the premenopausal (20-49 years), the menopausal (50-59 years) and the elderly (60 years or older, in line with prior report [13]). To compare proportional differences between age groups, $\chi^{2}$ test was used. Primary endpoint was DMFS, measured from treatment to the first distant metastasis or last contact. Other endpoints included CSS (time from treatment to death from cancer and treatment complication or last contact), OS (time from treatment to death from any cause or last contact) and LRFS (time from treatment to the first locoregional relapse or last contact). KaplanMeier method [14] and log-rank test were used to examine survival outcomes across age groups. Cox proportional hazard models [15] were used to evaluate associations between covariates and endpoints. All statistical analyses were performed using Stata 14 . Two-sided $P$ values $<0.05$ were considered to be significant.

\section{CONFLICTS OF INTEREST}

The authors have declared no conflicts of interest.

\section{GRANT SUPPORT}

This study was partly supported by the Guangdong Science and Technology Plan projects (No.2013B022000093).

\section{REFERENCES}

1. Ouyang PY, Su Z, Ma XH, Mao YP, Liu MZ and Xie FY. Comparison of TNM staging systems for nasopharyngeal carcinoma, and proposal of a new staging system. Br J Cancer. 2013; 109(12):2987-2997.

2. Li AC, Xiao WW, Shen GZ, Wang L, Xu AA, Cao YQ, Huang SM, Lin CG, Han F, Deng XW and Zhao C. Distant metastasis risk and patterns of nasopharyngeal carcinoma in the era of IMRT: long-term results and benefits of chemotherapy. Oncotarget. 2015; 6(27):24511-24521. doi: 10.18632/oncotarget.4312.

3. Zhang LN, Gao YH, Lan XW, Tang J, OuYang PY and Xie FY. Effect of taxanes-based induction chemotherapy in locoregionally advanced nasopharyngeal carcinoma: A large scale propensity-matched study. Oral Oncol. 2015; 51(10):950-956.

4. Zhang L, Tang LQ, Chen QY, Liu H, Guo SS, Liu LT, Guo L, Mo HY, Zhao C, Guo X, Cao KJ, Qian CN, Zeng MS, et al. Plasma Epstein-Barr viral DNA complements TNM classification of nasopharyngeal carcinoma in the era of intensity-modulated radiotherapy. Oncotarget. 2016; 7(5):6221-6230. doi: 10.18632/oncotarget.6754.

5. Yip TT, Ngan RK, Fong AH and Law SC. Application of circulating plasma/serum EBV DNA in the clinical management of nasopharyngeal carcinoma. Oral Oncol. 2014; 50(6):527-538.

6. OuYang PY, Zhang LN, Lan XW, Xie C, Zhang WW, Wang QX, Su Z, Tang J and Xie FY. The significant survival advantage of female sex in nasopharyngeal carcinoma: a propensity-matched analysis. Br J Cancer. 
2015; 112(9):1554-1561.

7. Fountzilas G, Ciuleanu E, Bobos M, Kalogera-Fountzila A, Eleftheraki AG, Karayannopoulou G, Zaramboukas T, Nikolaou A, Markou K, Resiga L, Dionysopoulos D, Samantas E, Athanassiou H, Misailidou D, Skarlos D and Ciuleanu $T$. Induction chemotherapy followed by concomitant radiotherapy and weekly cisplatin versus the same concomitant chemoradiotherapy in patients with nasopharyngeal carcinoma: a randomized phase II study conducted by the Hellenic Cooperative Oncology Group (HeCOG) with biomarker evaluation. Ann Oncol. 2012; 23(2):427-435.

8. Lee AW, Lau WH, Tung SY, Chua DT, Chappell R, Xu L, Siu L, Sze WM, Leung TW, Sham JS, Ngan RK, Law SC, Yau TK, et al. Preliminary results of a randomized study on therapeutic gain by concurrent chemotherapy for regionallyadvanced nasopharyngeal carcinoma: NPC-9901 Trial by the Hong Kong Nasopharyngeal Cancer Study Group. J Clin Oncol. 2005; 23(28):6966-6975.

9. Lee AWM, Ng WT, Chan LK, Chan OSH, Hung WM, Chan CC, Cheng PTC, Sze H, Lam TS and Yau TK. The strength/weakness of the AJCC/UICC staging system (7th edition) for nasopharyngeal cancer and suggestions for future improvement. Oral Oncol. 2012; 48(10):1007-1013.

10. Chen QY, Wen YF, Guo L, Liu H, Huang PY, Mo HY, Li NW, Xiang YQ, Luo DH, Qiu F, Sun R, Deng MQ, Chen MY, et al. Concurrent chemoradiotherapy vs radiotherapy alone in stage II nasopharyngeal carcinoma: phase III randomized trial. J Natl Cancer Inst. 2011; 103(23):17611770.

11. Sun X, Su S, Chen C, Han F, Zhao C, Xiao W, Deng $\mathrm{X}$, Huang S, Lin C and Lu T. Long-term outcomes of intensity-modulated radiotherapy for 868 patients with nasopharyngeal carcinoma: An analysis of survival and treatment toxicities. Radiother Oncol. 2014; 110(3):398403.

12. Li L, Wu J, Pu D, Zhao Y, Wan C, Sun L, Shen CE, Sun W, Yuan Z, Shen Q, He X, Jiang J, Luo N, et al. Factors associated with the age of natural menopause and menopausal symptoms in Chinese women. Maturitas. 2012; 73(4):354-360.

13. Zeng Q, Xiang YQ, Wu PH, Lv X, Qian CN and Guo X. A matched cohort study of standard chemo-radiotherapy versus radiotherapy alone in elderly nasopharyngeal carcinoma patients. PLoS One. 2015; 10(3):e0119593.

14. Kaplan EL and Meier P. Nonparametric estimation from incomplete observation. J Am Stat Assoc. 1958; 53:457481 .

15. Cox DR. Regression models and life tables. J R Stat Soc B. 1972; 34:187-220.

16. Xiao G, Cao Y, Qiu X, Wang W and Wang Y. Influence of gender and age on the survival of patients with nasopharyngeal carcinoma. BMC Cancer. 2013; 13(1):226.

17. Zhang LN, Tang J, Lan XW, OuYang PY and Xie FY.
Pretreatment anemia and survival in nasopharyngeal carcinoma. Tumour Biol. 2016; 37(2):2225-2231.

18. Liu H, Chen QY, Guo L, Tang LQ, Mo HY, Zhong ZL, Huang PY, Luo DH, Sun R, Guo X, Cao KJ, Hong MH and Mai HQ. Feasibility and efficacy of chemoradiotherapy for elderly patients with locoregionally advanced nasopharyngeal carcinoma: results from a matched cohort analysis. Radiat Oncol. 2013; 8:70.

19. Loong HH, Ma BB, Leung SF, Mo F, Hui EP, Kam MK, Chan SL, Yu BK and Chan AT. Prognostic significance of the total dose of cisplatin administered during concurrent chemoradiotherapy in patients with locoregionally advanced nasopharyngeal carcinoma. Radiother Oncol. 2012; 104(3):300-304.

20. Guo R, Mao YP, Chen L, Tang LL, Zhou GQ, Liu LZ, Tian L, Zeng MS, Jia WH, Shao JY, Lin AH and Ma J. Implication of comorbidity on the initiation of chemotherapy and survival outcomes in patients with locoregionally advanced nasopharyngeal carcinoma. Oncotarget. 2016; doi: 10.18632/oncotarget.8621. 